\title{
Decrease in Operation Temperature of Zinc Oxide Nanomarkers
}

\author{
VM Aroutiounian* \\ Yerevan State University, Yerevan, Armenia \\ *Corresponding author: VM Aroutiounian, Yerevan State University, Yerevan, Armenia
}

\section{ARTICLE INFO}

Received: 慧 August 28, 2020

Published: 豐 September 09, 2020

Citation: VM Aroutiounian. Decrease in Operation Temperature of Zinc Oxide Nanomarkers. Biomed J Sci \& Tech Res 30(2)-2020. BJSTR. MS.ID.004919.

Keywords: Semiconductor; Nanosensors; Impurities; Sensors; UV Light; Microelectronic Circuits

\section{ABSTRACT}

The review discusses the results of studies of gas nanosensors based on zinc oxide. Possibilities and technologies for the manufacture of such markers are mentioned. $\mathrm{ZnO}$ sensors undoped, doped with impurities and carbon nanotubes, as well as markers based on nanowires and quantum dots are considered. Possibilities of decreasing the operating (working) temperature of heating the workingbody of the sensors while maintaining a sufficiently high sensitivity to gases are shown. Recently developed ZnO markers are operating at room temperature (without preheating their working body) in the absence of and under UV light from the sensor.

Abbreviations: OT: Operating Temperature; ZnO: Zinc Oxide;0D:Zero- Dimensional; 1D: One-Dimensional; NRs: Nanorods; NWs:Nanowires; 2D: Two Dimensional Nanosheets; 3D: Three-Dimensional; MWCNT: Multi-Walled Carbon Nanotube; PG: Propylene Glycol; DMF: Dimethyl Phosphate;FA: Formaldehide; UV: Ultraviolet

\section{Introduction}

A lot of publications and patents about semiconductor gas sensors are published today in several scientific journals, materials of many Meetings, etc. Confine ourselves only of citations of four books published in the field [1-4]. The information about commercially available sensors based on metal oxides and produced in the USA, and Japan can be found in www.figarosensor.com, www. honeywell.com, www.sinkera.com, etc. All mentioned gas sensors need in high pre-heating of work semiconductor body, i.e. rather high consumption of electric energy. The lack of selectivity and long-term stability also often limit their applications. The range of the operating temperature (OT) of commercial gas sensors spans several hundred grads ${ }^{\circ} \mathrm{C}$. The problem today is the development of new semiconductor gas nano sensors working at or nearby room temperature of work body (practically without its pre-heating) and the use of small-size metal oxides sensors functionalized (decorated) with different impurities or nanotubes, covered by noble metal coatings. Nanoscale sensor applications secured the increase of the specific surface area and further advantages. In addition, today's sensors should be cheap and have possibilities to its inclusion into microelectronic circuits.

Today the gas sensitivity of thin-film structures made of different metal oxide materials $\left(\mathrm{SnO}_{2}, \mathrm{ZnO}, \mathrm{TiO}_{2}, \mathrm{WO}_{3}, \mathrm{In}_{2} \mathrm{O}_{3}\right.$,
$\mathrm{CuO}, \mathrm{NiO}, \mathrm{Fe}_{2} \mathrm{O}_{3}, \mathrm{Co}_{3} \mathrm{O}_{4}, \mathrm{~V}_{2} \mathrm{O}_{5}, \mathrm{ZnSnO}_{3}$, etc.) are studied widely [17]. Among the metal oxides, $\mathrm{ZnO}$ is proven as one of the best candidates for gas sensing applications due to its excellent stuff of tunable sensing parameters such as sensitivity, selectivity and stability, and good reliability, in addition to its non-toxic nature, controlled morphology, transparency in the visible range, a rather high electron mobility, cost-effectiveness and biocompatibility. Zinc oxide ( $\mathrm{ZnO})$ has a wide bandgap of $3.37 \mathrm{eV}$. It has aroused wide attention from scientists [8-16], and has potential applications as UV photodetectors [10], light-emitting diodes [13], solar cells [14], varistors, phosphor for color displays, heat mirrors, piezoelectric devices, surface acoustic wave devices, etc. $[15,16]$. ZnO was used as catalysts in past decades because of its special electrical, optical and catalytic properties. The concept of gas sensors using $\mathrm{ZnO}$ thin films was first proposed by Seiyama et al. [15].

\section{Non-Doped and Doped with Impurities and Carbon Nanotubes Zno Sensors}

Gas sensors based on non-doped $\mathrm{ZnO}$ have substantial drawbacks as high OTs (normally between 300 and $500^{\circ} \mathrm{C}$ ), a poor gas selectivity and a comparatively low gas sensitivity. To overcome these disadvantages, considerable disadvantages, considerable investigations are carried out. One critical issue in metal oxides gas 
sensors devices is a control the electronic and structural properties of the materials in order to modify the sensing properties. There are various techniques for modifying these properties. It is known that ruthenium in tin oxide matrix acts as an oxidative catalyst for hydrocarbons to achieve a considerable degree of sensitivity and selectivity. Therefore, an interesting approach is a modification of metal oxide surfaces using noble metal catalysts like $\mathrm{Pt}, \mathrm{Ru}$ and $\mathrm{Pd}$ (see for example, $[1,6]$ ).

Another way to improve of characteristics of sensors is the appropriate doping of metal oxides with different metal impurities. Aluminum-doped $\mathrm{ZnO}$ thin films were manufactured in $[16,17]$ on glass-ceramic substrates by the high- frequency magnetron sputtering method. The obtained $\mathrm{ZnO}<\mathrm{Al}>$ thin films have nanosize grains $(\sim 20-30 \mathrm{~nm})$. The glass ceramic/ZnO $<\mathrm{Al}>/$ Pt structure showed sufficient sensitivity to hydrogen at the heating of the working body already up to $400^{\circ} \mathrm{C}$. The investigations have shown that this structure has fast response and recovery time periods. We have shown that in contrast to many other metal-oxide materials, using our aluminum-doped $\mathrm{ZnO}$ films, it is possible to realize hydrogen sensors with remarkable low OT of pre-heating of the working body. The structure obtained satisfies the basic requirements to gas sensors. Analysis of the literature in [16] shown that $\mathrm{ZnO}$ nanorods sensors for detection of ethanol and hydrogen have $\mathrm{OT}=350^{\circ} \mathrm{C}[18], \mathrm{ZnO}$ nanowire sensors for detection of ethanol $300^{\circ} \mathrm{C}$ [19], $\mathrm{ZnO}$ thin film sensors for detection of methane $150-350^{\circ} \mathrm{C}$ [20] and ethanol [21], $\mathrm{Fe}_{2} \mathrm{O}_{3}$ - $\mathrm{ZnO}$ sensors for detection of $\mathrm{NH} 3350^{\circ} \mathrm{C}$ [22], ZnO sensors for detection of LPG $400^{\circ} \mathrm{C}$ [23], $\mathrm{ZnFe} 204$ sensors for detection of ethanol and acetone $300^{\circ} \mathrm{C}$ [24].

The other two investigations of aluminium doped $\mathrm{ZnO}$ films were reported in $[25,26]$. Pre-heating of the working body NOx sensors reported in [27] was $100-300^{\circ} \mathrm{C}$. Thin-film hydrogen peroxide vapor sensors made from lantana-doped $\mathrm{ZnO}$ were manufactured using the high-frequency magnetron sputtering method [28]. Sensors made from La-doped doped ZnO exhibit a sufficient response to $10 \mathrm{ppm}$ of hydrogen peroxide vapors at the $220^{\circ} \mathrm{C}$ operating temperature. It was established that the dependencies of the response on hydrogen peroxide vapor concentration have a linear character for prepared structures at the $150^{\circ} \mathrm{C}$ operating temperature and can be used for determination of hydrogen peroxide vapor concentration. The response of such detectors of hydrogen peroxide vapors was dramatically increased after this pre-heating temperature of work body [27]. The indium was added to increase the $\mathrm{ZnO}$ resistive response and reduce the operating temperature of the $3 \mathrm{D} \mathrm{ZnO} \mathrm{sensor.} \mathrm{The} \mathrm{highest} \mathrm{sensitivity}$ and selectivity toward ethanol gas at $250^{\circ} \mathrm{C}$ was observed for 5 at. $\%$ In doped ZnO. The response was about three times higher than that of the pure $\mathrm{ZnO}$ at $285^{\circ} \mathrm{C}$, which was probably connected with the unique 3D ordered macroporous morphology of the $\mathrm{ZnO}$ : In, increased surface area and higher electron carrier concentration $[28,29] . \mathrm{Mn} / \mathrm{ZnO} / \mathrm{Au} / \mathrm{ZnO}, \mathrm{Ag} / \mathrm{Al}-\mathrm{ZnO}$ sensors of acetone and formaldehyde at $\mathrm{OT}=\mathrm{t} 240-275^{\circ} \mathrm{C}$ were reported in [30-33]. Porous
$\mathrm{ZnO}$ acetone sensor with polymer colloids and $\mathrm{OT}=300^{\circ} \mathrm{C}$ was proposed in [34].

\section{Nanorod and Quantum Dots Markers}

We discuss below dimensional effects in small-size sensors. They are very important for modern microelectronics and measurement technics. Today the following small-size nanosensors are known: zero- dimensional (OD); one-dimensional (1D) nanorods (NRs) and nanowires (NWs); two dimensional (2D) nanosheets and films; three-dimensional (3D) porous nanostructures; three-dimensional (3D) nanostructures functionalized (decorated) with nanotubes. ZnO nanofibers, nanoplates, nanoflowers have been successfully synthesized by simple electrospinning hydrothermal routes and other methods [4]. One dimensional (1D) nanomaterials including nanowires, nanofibers, nanorods, and nanotubes have attracted great attention for sensing applications due to their unique morphology and the high surface-to-volume ratio [35]. Significant enhancement of hydrogen-sensing properties of $\mathrm{ZnO}$ nanofibers through $\mathrm{NiO}$ loading and $\mathrm{ZnO}$ nanowires decorated with $\mathrm{WO}_{3}$ nanoparticles [36]. Sensor based on 1D fluorine-doped zinc oxide (1D-FZO) was reported in [37]. A sensitive $\mathrm{H}_{2} \mathrm{~S}$ gas sensor made of $\mathrm{ZnO}$ QDs of less than $4 \mathrm{~nm}$ in diameter was fabricated in [38].

The average QD' grain size was below twice the Debye length. High sensitivity (Rair/Rgas) of 75 and 567 at room temperature and $90^{\circ} \mathrm{C}$, correspondingly, was realized. Microwave-assisted hydrolysis preparation of highly crystalline $\mathrm{ZnO}$ nanorod array was proposed in [39] for the manufacture of room temperature photoluminescence-based CO gas sensor. Nanotubes have attracted great attention as promising nanostructures for fabricating highly sensitive and selective gas sensors due to their vast surface area. In fact, the meso- and nanosized pores formed on various nanotubes surfaces during synthesis can significantly enhance the gas sensing performance by facilitating the penetration of targeting gas into the deepest parts of the sensing device. It was shown in Yerevan State University $[6,16,40]$ that the functionalization of multi-walled carbon nanotube (MWCNT) / $\mathrm{SnO}_{2}$ thick-film structures with $\mathrm{Ru}$ leads to a considerable increase in response signal to methanol, ethanol, acetone, toluene vapors as well as to isobutane gas.

Structures were obtained by hydrothermal synthesis and solgel techniques as well as their combination. Complicate phenomena processes took place in such functionalized nanocomposites, that can be considered as solid solutions of the metal oxide-other materials. The full picture is not possible to propose today, but we have to take into account the following: MWCNTs have a huge specific surface area and a nanoscale structure, which exposes a large number of sites at which the gases can react. Detection of various gases can be provided at low temperatures of pre-heating of the working body of a sensor. The electric conductivity of CNTs is much higher in comparison with the conductivity of metal oxides. Response of $\mathrm{SnO}_{2}$ /MWCNT sensors to propylene glycol (PG), dimethyl phosphate (DMF), and formaldehide (FA) vs OT is shown 
in (Figures $1 \& 2$ ) Dependencies of response and recovery times on OT are shown in (Figures 3-4).

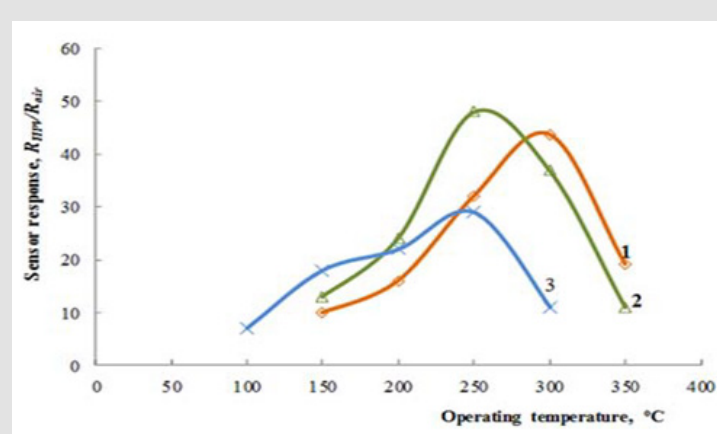

Figure 1: Dependence of the response to $1800 \mathrm{ppm}$ of hydrogen peroxide vapors on operating temperature for the $\mathrm{Zn} 0.9929 \mathrm{La} 0.00710$ sensors on alumina substrate with films thicknesses of $80 \mathrm{~nm}$ and

a. $210 \mathrm{~nm}$ and

b. for the marker with $\mathrm{Zn} 0.9853 \mathrm{La} 0.0147 \mathrm{O}$ films deposited on Multi-Sensor-Platform

c. [27].

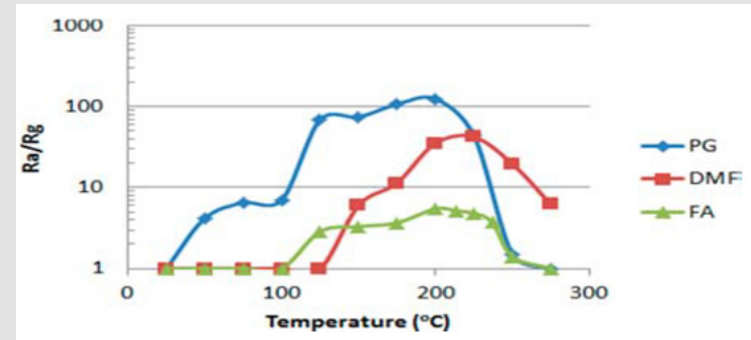

Figure 2: Response of $\mathrm{SnO}_{2} / \mathrm{MWCNT}$ sensors to propylene glycol (PG), dimethyl phosphate DMF), and formaldehide (FA) on temperature.

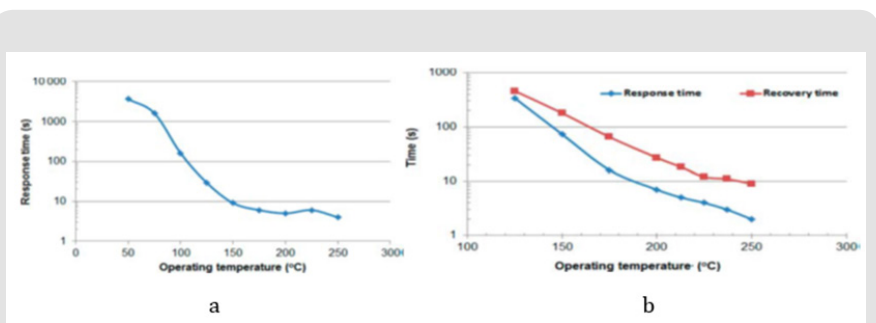

Figure 3: Response and recovery times of $\mathrm{SnO}_{2} / \mathrm{MWCNT}$ PG vapor sensor vs operating temperature.

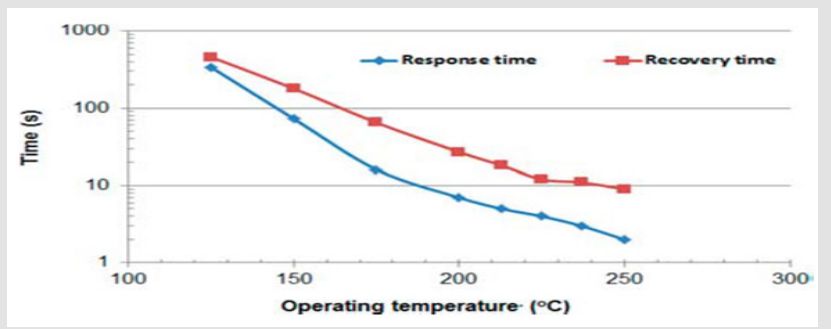

Figure 4: Recovery time of $\mathrm{SnO}_{2} / \mathrm{MWCNT}$ PG vapor sensor vs operating temperature.
Therefore, CNTs reduce the resistance of the sensing metal oxide materials and opens a possibility for the percolation of charge carriers through the sample. Since a $\mathrm{SnO}_{2}$ and $\mathrm{ZnO}$ has n-type and MWCNTs - p-type conductivity, there are two depletion layers in such hybrid films. The first depletion region is located at the metal oxide surface and the second one is located in the interface between the metal oxide nanoparticle and the MWCNTs. Formation of nanochannels and heterojunctions lead to enhanced gas sensitivity of such hybridized gas sensors as the decrease in the work function (barrier height) or increase in the conductivity of the metal oxide sensitive layer lead to the improvement in the performance of the gas sensor at low operating temperature [41,42]. Apparently, the discussed possible mechanisms require further experimental and theoretical investigations. Note that the highest sensitivity was achieved for $\mathrm{SnO}_{2}$ loaded in $0.25 \%$ MWCNTs. The over-addition of MWCNTs in the composite decreases the resistance of the sensor sharply.

For over-addition of MWCNTs, the increasing number of electrons in the grain boundary reduce the resistance and decrease the sensitivity of the metal oxide + MWCNT sensors. Similar behavior is also reported for $\mathrm{NO}_{2}$ by Sharma et al. [43]. The response toward acetone vapor was jumped to $72 \%$ after addition of $0.25 \%$ MWCNT also. Note that nanonsensors to hydrogen dioxide made from $\mathrm{SnO}_{2} /$ MWCNT were reported also in [44-51] and ZnO/CNTin [49]. ZnO nanoflowers acetone and $\mathrm{ZnO}$ hollow microspheres ethanol sensors with high OT reported in [50-52]. ZnO with 3D hierarchical mesoporous morphologies with high porosity, a large surface-to-volume ratio, is considered as a good candidate for gas sensing applications. Lupan et al. [53] have prepared porous 3D hybrid $\mathrm{ZnO}$ tetrapods by the flame transport method. They used different metallic ( $\mathrm{Fe}, \mathrm{Cu}, \mathrm{Al})$ microparticles with $\mathrm{ZnO}$. The sensor based on $\mathrm{ZnO} / \mathrm{CuO}$ (ZnO:Cu 20:1) shows a good resistive response at $350^{\circ} \mathrm{C}$ to $100 \mathrm{ppm}$ ethanol gas.

Acharyya et al. [54] have prepared 3D PdO-ZnO porous nanoflowers by using a liquid phase deposition method. Such PdO-ZnO structures showed an excellent response and recovery times for different alcohol vapors (0.5-700ppm). Their improved selectivity connected probably to the formation of a heterojunction junction, and lower activation energies for adsorption of methanol. Wang et al. [55] have prepared a 3D ordered macroporous $\mathrm{ZnO}$ nanostructure with a large surface area. Such $\mathrm{ZnO}$ based coreshell heterostructures showed higher gas response toward formaldehyde in comparison to those of other VOCs. It can be explained with the increase of the kinetic diameter of all detected VOCs in the order: formaldehyde $(0.243 \mathrm{~nm})<$ ammonia $(0.29 \mathrm{~nm})$ $<$ methanol $(0.363 \mathrm{~nm})<$ ethanol $(0.453 \mathrm{~nm})<$ acetone $(0.46 \mathrm{~nm})<$ toluene $(0.525 \mathrm{~nm})$ [56]. Also, the $\mathrm{ZnO}$-based gas sensors exhibit a low response for ammonia. Katoch et al. [57] prepared $\mathrm{TiO}_{2} / \mathrm{ZnO}$ double-layer hollow fibers on polymer fibers using an atomic layer deposition technique. They have superior sensing response toward $\mathrm{CO}$ and other reducing gases. 
A low-OT $\mathrm{H}_{2}$ Gas Sensor based on Pt-loaded reduced Graphene Oxide/ZnO nanocomposites was reported in [58]. The obtained RGO/ZnO/Pt ternary composite exhibits outstanding sensing response towards $\mathrm{H}_{2}$, almost 7.5 times and 3.0 times higher than that of pure $\mathrm{ZnO}$ and $\mathrm{ZnO} / \mathrm{RGO}$, respectively (Figure 5). The ethanolsensing properties of the $\mathrm{SnO}_{2} / \mathrm{ZnO}$ hierarchical nanostructures sensors were systematically investigated and compared to those of the bare $\mathrm{SnO}_{2} \mathrm{NWs}$ sensor in [59]. The results revealed that the design of the hierarchical nanostructures enhanced the ethanol gas response and selectivity for interfering gases such as $\mathrm{NH}_{3^{\prime}} \mathrm{CO}, \mathrm{H}_{2}$, $\mathrm{CO}_{2}$, and LPG. The $\mathrm{NH}_{3}$ gas-sensing properties of $\mathrm{ZnO}, \mathrm{SnO}_{2}$, and $\mathrm{WO}_{3} \mathrm{NWs}$ were investigated and compared in [60]. It was found that the responses and recovery time of $\mathrm{SnO}_{2}$ and $\mathrm{WO}_{3} \mathrm{NWs}$ sensors to $\mathrm{NH}_{3}$ gas are relatively comparable, and they have a better $\mathrm{NH}_{3}$ gassensing performance than that of $\mathrm{ZnO}$ NWs sensor. The $\mathrm{SnO}_{2} \mathrm{NWs}$ sensor has the lowest OT. $\mathrm{SnO}_{2} / \mathrm{ZnO}$ hetero nanofiber was exhibited high performance for acetone gas sensing due to very high toxicity of acetone, it is proposed to use thin layer $\mathrm{ZnO} / \mathrm{SnO}_{2} / \mathrm{Yb}_{2} \mathrm{O}_{3} \mathrm{NPs}$ [61]. Typical TEM and SEM images of QDs, nanorods, nano-sheets, microcubes and ultra porous film are shown in (Figures 6 \& 7) $[34,62-66]$.

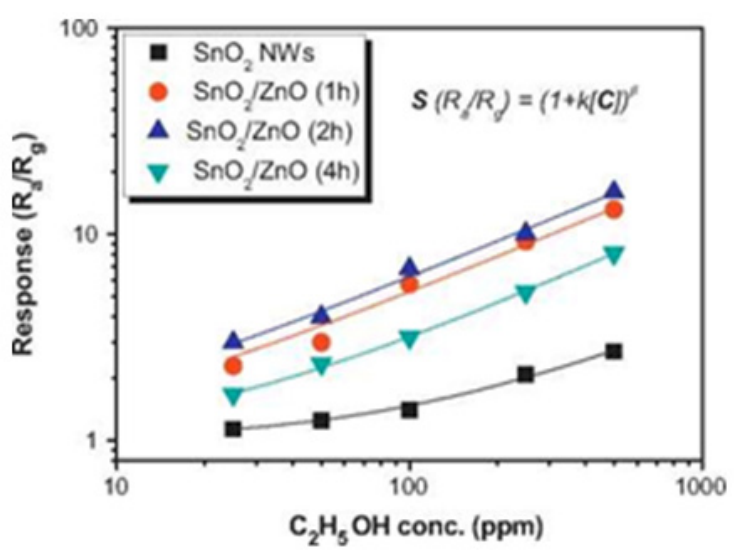

Figure 5: Ethanol response of the bare $\mathrm{SnO}_{2}$ nanowires and the $\mathrm{SnO}_{2} / \mathrm{ZnO}$ hierarchical nanostructures sensors as a function of ethanol gas concentration.

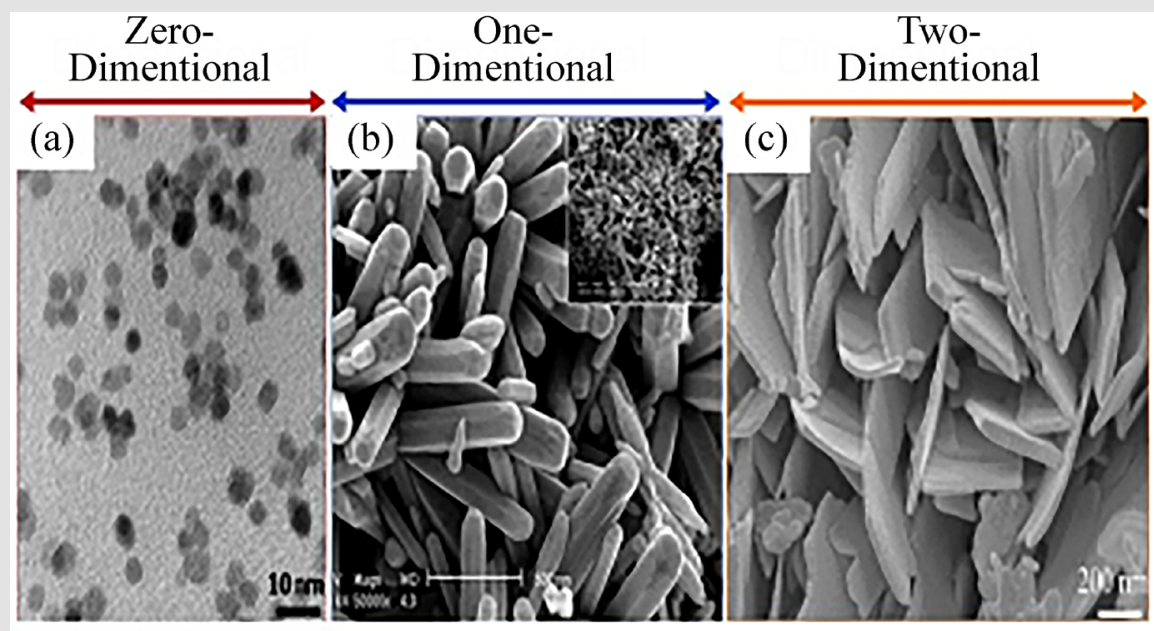

Three-Dimentional

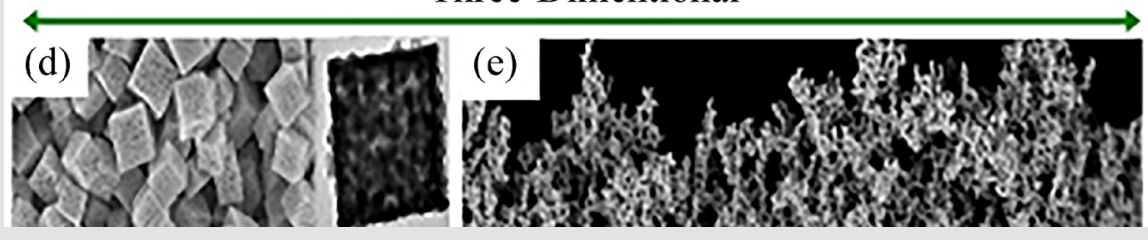

Figure 6:

a. Typical TEM image of ZnO QDs obtained through a wet synthesis method based on alkaline activated hydrolysis and condensation of zinc acetate solutions [62].

b. $\quad \mathrm{SEM}$ images of $\mathrm{ZnO}$ nanorods bundles synthesized at $150^{\circ} \mathrm{C}$, over 4 hours [63].

c. SEM image of $\mathrm{ZnO}$ nano-sheets formed through a simple mixed hydrothermal synthesis method [64].

d. SEM images of acid washed porous $\mathrm{SnO}_{2}$ microcubes after calcination at $900^{\circ} \mathrm{C}$ for 2 hours. Inset: TEM image of the asprepared porous $\mathrm{SnO}_{2}$ microcubes [65].

e. $\quad$ ZnO ultraporous film made by flame spray pyrolysis [66]. 


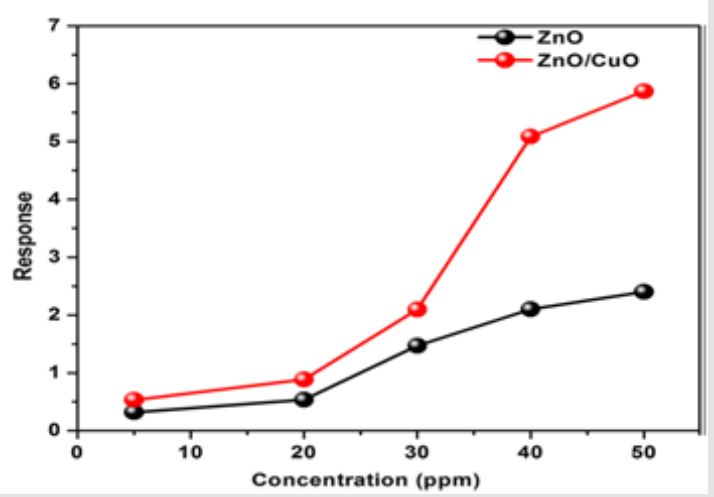

Figure 7: Comparison of ethanol response of $\mathrm{ZnO}$ and $\mathrm{ZnO} / \mathrm{CuO}$ Structures.

\section{Zn0 Sensors Without Pre-Heating of Their Work Body}

Recently sensors based on solid solutions of $\mathrm{ZnO}$ with different metal or graphene oxides were developed which did not need in pre-heating of work body of such sensors. A NiO (p-type)/ ultraporous (n-type)/ZnO nanostructured film with the rapid room temperature sensing of ethanol was fabricated by Chen et al. [67]. The thick ZnO film with $98 \%$ porosity with the thickness about $120 \mathrm{~nm}$ was deposited on a glass substrate featuring. Then the sputtered $\mathrm{NiO}$ nanoclusters were penetrated to the $\mathrm{ZnO}$ and form a homogeneous p-n heterojunction. In result, such nanosensor with interdigitated Pt electrodes had enhanced sensing response at $10 \mathrm{ppb}$ toward ethanol at room temperature. Mesoporous $\mathrm{ZnO}$ nanosheets were also used for preparation of superior humidity sensor and photodetector working at room temperature [68]. The room temperature $\left(29^{\circ} \mathrm{C}\right)$ ethanol sensor based on vertically aligned $\mathrm{ZnO}$ nanorods decorated with $\mathrm{CuO}$ nanoparticles was successfully fabricated in in [69]. The vertical alignment of $\mathrm{ZnO}$ nanorods as well as its surface modification by $\mathrm{CuO}$ nanoparticles increased the effective surface area of the device and the formation of $p-\mathrm{CuO} / n-\mathrm{ZnO}$ heterojunction at the interface are the reasons for the improved performance at room temperature. In addition to ethanol, the fabricated device has the capability to detect the presence of reducing gases like hydrogen sulfide and ammonia at room temperature but the response is less.

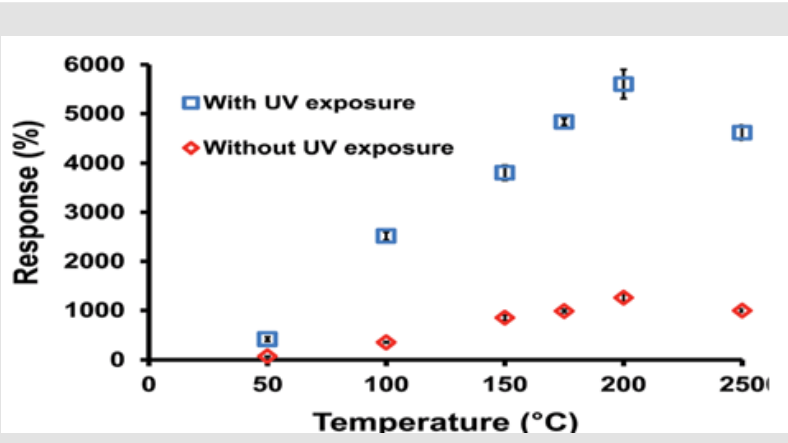

Figure 8: The measured sensing responses of $\mathrm{Zn}$ Onanorods under various operation temperatures
Pure $\mathrm{ZnO}$ thick film, prepared by screen-printing technique, was almost insensitive to $\mathrm{NH}_{3}$. The $\mathrm{MnO}_{2}$ modified $\mathrm{ZnO}$ films were sensitive and highly selective to $\mathrm{NH}_{3}$ gas at room temperature. An exceptional sensitivity was found to low concentration (50ppm) of $\mathrm{NH}_{3}$ gas at room temperature and no cross sensitivity was observed even to high concentrations of other hazardous and polluting gases. The effects of surface microstructure and $\mathrm{MnO}_{2}$ concentrations on the sensitivity, selectivity, response and recovery of the sensor in the presence of $\mathrm{NH}_{3}$ and other gases were studied and discussed in [70]. A highly selective room temperature ammonia sensor using spray deposited zinc oxide thin film was reported in [71] on glass substrates by spray pyrolysis technique. Response and recovery times of 20 and 25 s respectively were observed with the high response of 233 towards $25 \mathrm{ppm}$ of $\mathrm{NH}_{3}$ vapor. It is known that breathing $\mathrm{NO}_{2}$ and $\mathrm{O}_{3}$ can trigger a variety of human health problems, for example, excessive inhalation of $\mathrm{NO}_{2}$ at a concentration greater than $1 \mathrm{ppm}$ can cause pulmonary disease and severe damage to the respiratory system. Prolonged exposure to $\mathrm{O}_{3}$ concentrations of $375 \mathrm{ppb}$ and higher may cause both acute and chronic diseases, such as upper respiratory infection or chronic respiratory and heart disease. Therefore, it is urgent to further the development of gas sensors to detect and identify oxidizing gases $\left(\mathrm{NO}_{2}\right.$ and $\left.\mathrm{O}_{3}\right)$ already at low concentrations.

$\mathrm{NO}_{2}$ gas sensing properties of conducting polymer $\mathrm{Au}$ loaded $\mathrm{ZnO}$ nanoparticle composite materials at room temperature were studied for ammonia sensing applications [72]. Such nanocomposite hybrid thin films showed a high relative response of 2.2 to $200 \mathrm{ppb}$ of $\mathrm{NO}_{2}$ but virtually no response to $\mathrm{CO}$ or $\mathrm{C}_{2} \mathrm{H}_{5} \mathrm{OH}$ and very small response to $\mathrm{NH}_{3}$ at room temperature. $\mathrm{ZnO}$ nanorods (NRs) and nanowires (NWs) were on-chip grown via a facile hydrothermal method and used for room-temperature $\mathrm{NO}_{2}$ gas sensor applications [73]. Results show that the diameter of $\mathrm{ZnO}$ NRs and NWs is the dominant parameter of their $\mathrm{NO}_{2}$ gas-sensing performance at room temperature. Hybrid material $\mathrm{Zn}_{2} \mathrm{SnO}_{4}$-RGO containing $\mathrm{Zn}_{2} \mathrm{SnO}_{4}$ nanoparticles (NPs) and immobilized reduced graphene oxide was developed in the [74] as a high-performance gas sensing material for the highly selective detection of ppb-levels of oxidizing gases $\left(\mathrm{NO}_{2}\right.$ and $\left.\mathrm{O}_{3}\right)$.

Highly selective oxidizing gas sensors are of great importance for environmental pollution monitoring. Moreover, $\mathrm{O}_{3}$ has significantly lower dissociation energy $(1.1-1.3 \mathrm{eV})$ than $\mathrm{O}_{2}(5.1 \mathrm{eV})[75,76]$. As a consequence, many metal oxides were extensively investigated for $\mathrm{O}_{3}$ sensing [77-79]. However, such sensors have the obvious disadvantage of high operating temperatures $\left(150-300^{\circ} \mathrm{C}\right)$. Therefore, $\mathrm{O}_{3}$ sensing properties of sensors based on metal oxide-RGO hybrids need to be further improved. A p-type RGO semiconductor is a desirable two-dimensional (2D) substrate for anchoring metal oxide NPs for gas sensing at room temperature, owing to oxygen-containing groups remaining on its surface, which act as adsorption sites for gas molecules [80,81]. At present, many new findings on $\mathrm{SnO}_{2}, \mathrm{In}_{2} \mathrm{O}_{3}$, and $\mathrm{Co}_{3} \mathrm{O}_{4}$ metal oxide modified RGO have been report- 
ed, which are applied in improving $\mathrm{NO}_{2}$ gas sensing performance [82-87]. Among many metal oxides, n-type $\mathrm{Zn}_{2} \mathrm{SnO}_{4}$ has received considerable attention because of its high electron mobility, high electrical conductivity and wide band gap $(3.6 \mathrm{eV})$, which make it suitable for gas sensor applications $[88,89]$. When $\mathrm{Zn}_{2} \mathrm{SnO}_{4}$ is coupled with RGO, its electrons can transfer from $\mathrm{Zn}_{2} \mathrm{SnO}_{4}$ to RGO. As a result, the effective electronic contact between $\mathrm{Zn}_{2} \mathrm{SnO}_{4}$ and RGO helps to improve the gas sensing performance. It was reported that $\mathrm{Zn}_{2} \mathrm{SnO}_{4} \mathrm{NWs}$ and $\mathrm{NO}_{2}$ NRs sensors have OT 200-300 ${ }^{\circ} \mathrm{C}$ [90-92], hierarchical RGO- $100^{\circ} \mathrm{C}$ [93], $\mathrm{Zn}_{2} \mathrm{SnO}_{4}-\mathrm{RGO}-30^{\circ} \mathrm{C}$ [74], but $\mathrm{ZnO}, \mathrm{PbS}$ and two-dimensional WS2, MoS2 based RGO are $\mathrm{NO}_{2}$ sensors at room temperature [74]. Detection limits are 0.05-0.15ppm.

In [74], a hybrid material containing $\mathrm{Zn}_{2} \mathrm{SnO}_{4} \mathrm{NPs}$ and immobilized reduced graphene oxide $\left(\mathrm{Zn}_{2} \mathrm{SnO}_{4}\right.$-RGO) were developed by members of Prof. U. Weimar' Lab. The $\mathrm{NO}_{2}$ sensing performances of $\mathrm{Zn}_{2} \mathrm{SnO}_{4}$-RGO-based sensors were investigated under various humidity $\mathrm{RH}$. Note that the sensors based on RGO and $\mathrm{Zn}_{2} \mathrm{SnO}_{4}$ - $\mathrm{RGO}$ hybrids have p-type behavior. The effect of humidity on $\mathrm{NO}_{2}$ sensing properties is lacking in the previous reports. The sensors based on $\mathrm{Zn}_{2} \mathrm{SnO}_{4}$-RGO hybrids also exhibited high response values of up to 3.62 for $1 \mathrm{ppm} \mathrm{NO}_{2}$ at $50^{\circ} \mathrm{C}$ in $80 \% \mathrm{RH}$, which is much higher than that of pure RGO (1.31). The excellent sensing performances are mainly ascribed to the synergetic effect of $\mathrm{Zn}_{2} \mathrm{SnO}_{4} \mathrm{NPs}$ and RGO. $\mathrm{Zn}_{2} \mathrm{SnO}_{4}$-RGO-based sensors exhibited enhanced sensitivity to $\mathrm{NO}_{2}$ (5.97 to $1 \mathrm{ppm} \mathrm{NO}$ ). Note that sensors based on WS2 nanosheets and PbS CQDs can detect $\mathrm{NO}_{2}$ with a lower detection limit of $0.1 \mathrm{ppm}$ and $1 \mathrm{ppm}[53,54]$, respectively. In contrast to that, the sensors presented in [74] not only show high sensitivity to lower concentrations of $\mathrm{NO}_{2}$ (2.86 for $150 \mathrm{ppb}$ in $50 \% \mathrm{RH}$ ) but are also able to retain this quality in a high humidity atmosphere (80\%). $\mathrm{NO}_{2}$ and $\mathrm{O}_{3}$ sensing mechanisms were discussed in details in [74].

\section{Decrease in Operating Temperature and Increase in Sensitivity of Sensors Under Illumination}

The PbS QDs-decorated ZnO NRs with a hierarchical mesoporous structure were investigated in [94]. The nanocomposites showed near-infrared (NIR) adsorption derived from the PbS QDs with a narrow bandgap. Compared to the pristine $\mathrm{ZnO}$ nanorods, the $\mathrm{ZnO} / \mathrm{PbS}$ nanocomposites-based sensor with the optimal loading amount of $\mathrm{PbS}$ exhibited higher response and quicker response/ recovery rates to ppm level of $\mathrm{NO}_{2}$ at room temperature under NIR illumination. Moreover, the sensor exhibited full reversibility, low detection limit, good selectivity, and long-term stability to $\mathrm{NO}_{2}$. In the last few years, it has been shown that UV enhances the gassensing properties of metal oxides at room temperature [95-100]. UV illumination reduces response and recovery times and increases sensitivity. By using $\mathrm{ZnO}$ as the sensor material, it is possible to measure ppb-level $\mathrm{NO}_{2}$ concentrations [101,102]. A transducer by which UV-supported metal oxide sensors can be miniaturized consuming only little energy has reported [103].
The gas-sensitive material adsorbs each $\mathrm{NO}_{2}$ molecule impinging on the surface and thus the sensor signal increases linearly with the $\mathrm{NO}_{2}$ dose. $\mathrm{ZnO}$-based dosimeter and concentration gas sensors with regeneration by UV light should be feasible. An experimental proof on sol-gel synthesized Al-doped $\mathrm{ZnO}$ sensors demonstrated in [104] that the sensor concept works at room temperature for ppb-level $\mathrm{NO}_{2}$ concentrations and low doses are given. A novel ultraviolet (UV) irradiation assisted nanostructured $\mathrm{ZnO}$ film for high performance oxygen sensing under at a temperature of $50^{\circ} \mathrm{C}$ was proposed in [105]. Nanorod ZnO structures with high exposing area are synthesized on a glass substrate with interdigital sensing electrodes via the developed two-stage sol-gel and hydrothermal processes. A UV-LED with an emission wavelength of $370 \mathrm{~nm}$ is used to enhance the sensing performance of the nanostructured $\mathrm{ZnO}$ film. The response of the UV-assisted ZnO film is 4.66 times larger than the same film without UV exposure. UV activated polycrystalline ZnO films on a flexible substrate (Kapton) were used in [106] for room temperature $\mathrm{O}_{2}$ and $\mathrm{H}_{2} \mathrm{O}$ sensing to detect and differentiate between environmental changes in oxygen and water vapor. $\mathrm{ZnO}$ films were fabricated from bacteria-derived $\mathrm{ZnS}$ nanoparticles. Under UV irradiation $\mathrm{O}_{2}$ reacted with photogenerated electrons resulting in chemisorption of ionic oxygen to the $\mathrm{ZnO}$ surface. Grain resistance and grain boundary capacitance of polycrystalline $\mathrm{ZnO}$ film dominates the response of both $\mathrm{O}_{2}$ and $\mathrm{H}_{2} \mathrm{O}$ in dark and under UV irradiation, while the response from the grain boundary resistance and grain capacitance are only significant under UV irradiation.

The ZnO nanowires/LED combination was used to fabricate an ethanol concentration sensor [100]. ZnO nanowires were hydrothermally synthesized on a silicone layer of an ultraviolet (UV) light-emitting diode (LED) ethanol sensing current of the sensor increased linearly with UV LED illumination at room temperature.

The effects of ZnO nanostructure morphology on the gassensing property of HCHO have been investigated in [107]. The gas sensor based on $\mathrm{ZnO}$ nanofibers showed high sensitivity, reversible response, and good selectivity towards $\mathrm{HCHO}$ under the irradiation of $365 \mathrm{~nm}$ UV-light at room temperature. These desirable sensing features can be attributed to the special network structure with larger specific surface areas and its one-dimensional arrangement of $\mathrm{ZnO}$ nanocrystallites with a larger proportion of the depletion layer, which results in more obvious adjustment of the depletion layer width. ZnO nanofibers obtained by the electrospinning are attractive chemical sensing materials. Note also that $\mathrm{SnO}_{2}$ doped with cobalt is a very promising material for the manufacture of hydrogen peroxide vapors sensor with room OT working under UV radiation [108].

\section{Some Information about Theoretical Investigations}

To date, many of the mechanisms of the gas adsorption process and the nature of active centers responsible for the adsorption of gases on the surface of metal oxide materials are far from fully 
understood. These processes are very complex and their theoretical analysis requires ab initio calculations of the adsorption energies, equilibrium geometry, and charge transfer between the surface and the adsorbent, based on the density functional theory (DFT) [109-112]. We performed calculations, in particular, based on the DFT implemented in the Quantum Espresso package [110-112]. We use the generalized gradient approximation (GGA) in the form suggested by Purdue, Burke, and Ernzerhof [113] to describe the exchange-correlation functional. We have so far investigated the interaction of hydrogen peroxide with the stoichiometric surface (110) of tin dioxide, in particular, we have studied the interaction of several starting configurations of $\mathrm{H}_{2} \mathrm{O}_{2}$ and the surface. Their structures, adsorption energies, and charge transfer between the molecule and the surface were calculated by the Bader charge analysis method [114]. Since defects, impurities, quantum-size effects, and gas molecules in the environment can have a significant effect on adsorption processes [115,116], additional research is needed to find out how all this can affect the process. An analysis of the latest book on quantum dots [117] shows no progress in studies of adsorption phenomena at the QD interface metal oxide - gas.

\section{References}

1. Jaanisco R, Tan OK (2013) (Eds.)., Semiconductor Gas Sensors. Woodhead Publishing Oxford, UK, pp. 552.

2. Lyshevski SE (2014) (Eds.). Encyclopedia of Nanoscience and Nanotechnology. CRC Press, USA.

3. Banika FG (2014) Chemical and biological sensors. Technosphera Press pp. 880.

4. Aroutiounian VM (2019) Gas nanosensors made from semiconductor metal oxides. J Cont Physics Arm Acad Sci 54: 356-367.

5. Aroutiounian VM (2020) Metal oxide gas biomarkers of diseases for medical and health applications. Biomed J Sci \& Tech Res 29: 2232822334.

6. Aroutiounian VM (2020) Microelectronic gas sensors for non-invasive analysis of exhaled gases. J Nanomedicine and Nanotechnology 11: 1-7.

7. Malik R, Vijay K, Tomer VK, Mishra YK and Lin L (2020) Functional gas sensing nanomaterials: A panoramic view. Appl Phys Rev 7: 021301.

8. Aroutiounian VM (2020) Experimental investigations of acetone sensors based on tin dioxide. J Nanomedicine Nanotechnology and Nanomaterials 1: 1-11.

9. Aroutiounian VM (2007) Metal oxide hydrogen, oxygen and carbon monooxide sensors for hydrogen setups and cells. Int J Hydrogen Energy 32(9); 1145-1158.

10. Aroutiounian VM, Adamyan AZ, Khachaturyan EA, Adamyan ZN, Hernadi K, et al. (2013) Study of the surface-ruthenated $\mathrm{SnO}_{2} / \mathrm{MWCNTs}$ nanocomposite thick-film gas sensors. Sensors and Actuators 177: 308315.

11. Wang ZL (2008) Splendid one-dimensional nanostructures of zinc oxide: a new nano-material family for nanotechnology. ACS Nano 2(10): 1987-1992.

12. Kumar MA, Jung S, Ji T (2011) Protein biosensors based on polymer nanowires, carbon nanotubes and zinc oxide nanorods. Sensors 11(5): 5087-5111.

13. Cleetus CM, Fabian Alvarez Primo, Gisel Fregoso, Nivedita Lalitha Raveendran, Juan C Noveron, et al. (2020) Alginate Hydrogels with Embedded ZnO Nanoparticles for Wound Healing Therapy. Int J Nanomedicine 15: 5097-5111.
14. Peng SM, Su YK, Ji LW, Wu CZ, Cheng WB, et al. (2010) ZnO nano bridge array UV photodetectors. J Phys Chem C 114(7): 3204-3208.

15. Lim JH, Kang CK, Kim KK, Park IK, Hwang DK, et al. (2006) UV electroluminescence emission from $\mathrm{ZnO}$ light-emitting diodes grown by high-temperature radiofrequency sputtering. Adv Mater 18(20): 27202724.

16. Sun Y, Seo JH, Takacs CJ, Seifter J, Heeger AJ (2011) Inverted polymer solar cells integrated with a low-temperature-annealed sol-gel-derived ZnO film as an electron transport layer. Adv Mater 23(14): 1679-1683.

17. Wei A, Pan L, Huang W (2011) Recent progress in the ZnO nanostructurebased sensors. Mater Sci Eng 176(18): 1409-1421.

18. Seiyama T, Kato A, Fjiishi K, Nagatani M (1962) A New Detector for Gaseous Components Using Semiconductive Thin Films. Anal Chem 34(11): 1502-1503.

19. Galstyan VE, Aroutiounian VM, Arakelyan VM, Shahnazaryan GE (2008) Investigation of hydrogen sensor made of $\mathrm{ZnO}<\mathrm{Al}>$ thin film. Arm J Phys 1: 242-246.

20. Aroutiounian VM, Arakelyan VM, Shahnazaryan GE, Galstyan VE, Alexanyan MS, et al. (2010) Investigation of hydrogen sensor made of $\mathrm{ZnO}<\mathrm{Al}>$ thin film. ISJAEE 3: 125-127.

21. Bie Li Jian, Yan Xiao Na, Yin Jing, Duan Yue Qin, Yuan Zhi Hao (2007) Nanopillar ZnO gas sensor for hydrogen and ethanol. Sensors and Actuators 126(2): 604-608.

22. Hsueh Ting Jen, Hsu Cheng Liang, Chang Shoou Jinn, Chen I Ch (2007) Laterally grown $\mathrm{ZnO}$ nanowire ethanol gas sensors. Ibid 126(2): 473477.

23. Bhattacharyya P, Basu PK, Saha H, Basu S (2007) Fast response methane sensor using nanocrystalline zinc oxide thin films derived by sol-gel method. Ibid 124: 62-67.

24. Kim Ki Won, Cho Pyeong Seok, Kim Sun Jung, Lee Jong Heun, Kang Chong Yun, et al. (2007) The selective detection of $\mathrm{C}_{2} \mathrm{H}_{5} \mathrm{OH}$ using $\mathrm{SnO}_{2} \mathrm{ZnO}$ thin film gas sensors prepared by combinatorial solution deposition. Ibid 123(1): 318-324.

25. Patil DR, Patil LA (2007) Ammonia sensing resistors based on $\mathrm{Fe}_{2} \mathrm{O}_{3}$ modified ZnO thick films. IEEE Sensors Journal 7(3): 434-439.

26. Shinde VR, Gujar TP, Lokhande CD, Mane RS, Han Sung Hwan (2007) Development of morphological dependent chemically deposited nanocrystalline $\mathrm{ZnO}$ films for liquefied petroleum gas (LPG) sensor. Sensors and Actuators 123(2): 882-887.

27. Navale SC, Ravia V, Mulla IS, Gosavi SW, Kulkarni SK (2007) Lowtemperature synthesis and NOx sensing properties of nanostructured Al-doped ZnO. Ibid 126(2): 382-386.

28. Aroutiounian V, Valeri Arakelyan, Mikayel Aleksanyan, Gohar Shahnazaryan, Petr Kacer, et al. (2018) Thin-film $\mathrm{SnO}_{2}$ and $\mathrm{ZnO}$ detectors of hydrogen peroxide vapors. J Sens Sens Syst 7: 281-288.

29. Z Wang, Z Tian, D Han, F Gu (2016) Highly sensitive and selective ethanol sensor fabricated with In-doped 3DOM ZnO. ACS Appl Mater Interfaces 8: 5466-5474.

30. J Xia, K Diao, Z Zheng, X Cui (2017) Porous Au/ZnO nanoparticles synthesised through a metal organic framework (MOF) route for enhanced acetone gas-sensing. RSC Adv 7: 38444-38451.

31. Darvishnejad MH, Anaraki Firooz A, Beheshtian J, Khodadadi AA (2016) Highly sensitive and selective ethanol and acetone gas sensors by adding some dopants (Mn, Fe, Co, Ni) onto hexagonal ZnO plates. Ibid 6: 7838.

32. X Xing, Y Li, D Deng, N Chen, X Liu, et al. (2016) Nanomaterial-based gas sensors: A review. RSC Adv 6: 101304.

33. HW Huang, Jing Liu, Guangfu He, Yao Peng, Min Wu, et al. (2015) Tunable macro-mesoporous $\mathrm{ZnO}$ nanostructures for highly sensitive ethanol and acetone gas sensors. Ibid 5: 101910 .

34. Alenezi MR, Henley SJ, Emerson NG, Silva SRP (2014) Single Hierarchical Nanostructure Metal Oxide. Gas Sensor Nanoscale 6: 235-247. 
35. Nasiri N, Bo R, Wang F, Fu L, Tricoli A (2015) Ultraporous electrondepleted $\mathrm{ZnO}$ nanoparticle networks for highly sensitive portable visible-blind UV photodetectors. Adv Mater 27(29): 4336-4343.

36. Lee J, Kim J, Mirzaei A, Woo Kim H, Kim SS (2018) Significantenhancement of hydrogen-sensing properties of $\mathrm{ZnO}$ nanofibers through $\mathrm{NiO}$ loading. Nanomaterials 8(11): 902-908.

37. Park S (2019) Enhancement of hydrogen sensing response of $\mathrm{ZnO}$ nanowires for the decoration with $\mathrm{WO}_{3}$. Materials Letters 234: 315-318.

38. Napi M, Sultan SM, Ismail R, Ahmad M, Chai G (2019) Optimization of a Hydrothermal Growth Process for Low Resistance 1D Fluorine-Doped Zinc Oxide Nanostructures. J Nanomaterials 2019: 4574507.

39. Tan ST, Chun Hui Tan, Akrajas Ali Umar, Riski Titian Ginting, Hock Beng Lee, et al. (2016) Microwave-assisted hydrolysis preparation of highly crystalline $\mathrm{ZnO}$ nanorod array for room temperature photoluminescencebased CO gas sensor. Sensors and Actuators 227: 304-312.

40. Aroutiounian V, Adamyan Z, Sayunts A, Khachaturyan E, Adamyan A, et al. (2014) Comparative study of VOC based on ruthenated sensors based on MWCNT $/ \mathrm{SnO}_{2}$ nanocomposites. Int J Emerging Trends in Science and Technology 1: 1309-1309.

41. Aroutiounian VM (2018) Semiconductor gas sensors made from metal oxides functionalized with carbon nanotubes. Sensors and Transducers 223: 9-21.

42. Aroutiounian VM (2015) Metal oxide gas sensors decorated with carbon nanotubes. Lith J Phys 55(6): 319-329.

43. Sharma A, Tomar M, Gupta V (2012) Zinc oxide-multiwalled carbon nanotubes hybrid nano composite based urea biosensor. J Mater Chem 22: 23608 .

44. Aroutiounian VM (2019) Gas Nanosensors Made from Semiconductor Metal Oxides. J Cont Phys Arm Acad Sci 54(4): 356-367.

45. Aroutiounian VM (2018) Functionalized with Carbon Nanotubes Semiconductor Gas Sensors Made from Metal Oxides. Sensors and Transducers 228(12): 1-16.

46. Z Adamyan, Artak Sayunts, Vladimir Aroutiounian, Emma Khachaturyan, Arsen Adamyan, et al. (2017) Study of Propylene Glycol, Dimethylformamideand Formaldehyde Vapors Sensors Based on MWCNTs $/ \mathrm{SnO}_{2}$ Nanocomposites. Sensors \& Transducers 213(6): 38-45.

47. Ahmadnia Feyzabad S, Khodadadi AA, Vesali Naseh M, Mortazavi Y (2012) Highly sensitive and selective sensors to volatile organic compounds using MWCNTs/SnO . Ibid 166-167: 150-155

48. Alvi MA, Madani J, Kumar A (2019) Synthesis and characterization of SWCNTs/ZnO hybrid nanocomposite for sensor applications. Mater Res Express 6(10): 1054

49. Salehi S, Nikan E, Khodadadi AA, Mortazavi Y (2014) Highly sensitive carbon nanotube- $\mathrm{SnO}_{2}$ nanocomposite sensor for acetone detection in diabetes mellitus breath Sens. Actuators 205: 261-267.

50. Zhang S, Chen HS, Matras Postolek K, Yang P (2015) ZnO nanoflowers with single crystal structure towards enhanced gas sensing and photocatalysis. Phys Chem Chem Phys 17(45): 30300.

51. Wang X, Minggang Zhao, Yawen Song, Qingyun Liu, Yongxing Zhang, et al. (2019) Synthesis of $\mathrm{ZnFe}_{2} \mathrm{O}_{4} / \mathrm{ZnO}$ heterostructures decorated threedimensional graphene foam as peroxidase mimetics for colorimetric assay of hydroquinone Sens. Actuators 283: 130-137.

52. Qiu J, Zhang R, Li J, Sang Y, Tang W, et al. (2015) Fluorescent graphene quantum dots as traceable, $\mathrm{pH}$-sensitive drug delivery systems. Int J Nanomedicine 10: 6709-6724.

53. Lupan V, Postica, V Postica, J Gröttrup, AK Mishra, et al. (2017) Hybridization of zinc oxide tetrapods for selective gas sensing applications. ACS Appl Mater Interfaces 9(4): 4084-4099.

54. Acharyya D, KY Huang, PP Chattopadhyay, MS Ho, HJ Fechte, et al. (2016) Hybrid 3D Structures of ZnO Nanoflowers and PdO Nanoparticles as a Highly Selective Methanol Sensor. Analyst 141: 2977-3004.
55. Wang Z, Han TD, Gu F (2016) Highly Sensitive and Selective Ethanol Sensor Fabricated with In-Doped 3DOM ZnO ACS Appl. Mater. Interfaces 8(8): 5466-5474.

56. Tian H, Fan M, Ma L (2016) Zeolitic Imidazolate Framework Coated ZnO Nanorods as Molecular Sieving to Improve Selectivity of Formaldehyde Gas Sensor ACS Sens 1(3): 243-250.

57. Katoch A, Kim JH, Kim SS (2014) Synthesis and gas sensing properties of membrane template-grown hollow $\mathrm{ZnO}$ nanowires. ACS Appl Mater Interfaces 6: 21494- 21499.

58. Drmosh QA (2018) A low Temperature $\mathrm{H}_{2}$ Gas Sensor Based on Pt loaded Reduced Graphene Oxide ZnO Nanocomposites. Proc $17^{\text {th }}$ International Meeting on Chemical Sensors.

59. Khoang ND, Do Dang Trung, Nguyen Van Duy, Nguyen Duc Hoa (2012) Design of $\mathrm{SnO}_{2} / \mathrm{ZnO}$ hierarchical nanostructures for enhanced ethanol gas-sensing performance. Sensors and Actuators 174: 594- 601.

60. Hieu NV, Dang Thi Thanh Le, Nguyen Duc Khoang, Nguyen Van Quy (2015) A comparative study on the $\mathrm{NH}_{3}$ gas-sensing properties of $\mathrm{ZnO}$, $\mathrm{SnO}_{2}$, and $\mathrm{WO}_{3}$ nanowires. J Nanomaterials 972025: 14 .

61. Mohammed M, Alam MM, Asiri AM, MA Islam (2017) Fabrication of selective chemical sensor with ternary $\mathrm{ZnO} / \mathrm{SnO} / \mathrm{Yb} 203$ nanoparticles. Talanta 170: 215-223.

62. Nasiri N, Clarke Ch (2019) Open Access Review Nanostructured Gas Sensors for Medical and Health Applications: Low to High Dimensional Materials Biosensors 9(1): 43-51.

63. Forleo A, Francioso L, Capone S, Siciliano P, Lommens P, et al. (2010) Synthesis and gas sensing properties of $\mathrm{ZnO}$ quantum dots. Sensors and Actuators 146(1): 111-115.

64. Kim J, Yong K (2011) Mechanism Study of ZnO Nanorod-Bundle Sensors for $\mathrm{H}_{2} \mathrm{~S}$ Gas Sensing. J Phys C 115(15): 7218-7224.

65. Fan H, Jia X (2011) Selective detection of acetone and gasoline by temperature modulation in zinc oxide nanosheets sensors. Solid State Ionics 192(1): 688-692.

66. E Vereshchagina, RM Tiggelaar, RGP Sanders, RAM Wolters, JGE Gardeniers (2015) Low power micro-calorimetric sensors for analysis of gaseous samples. Sensors and Actuators 206: 772-787.

67. Chen YL, Ling Yu, Dandan Feng, Ming Zhuo, Ming Zhang, et al. (2012) Superior ethanol-sensing properties based on Ni-doped $\mathrm{SnO}_{2} \mathrm{p}$-n heterojunction hollow spheres. Ibid 166-167: 61-67.

68. Shobhnath P, Amit S Pawbake, Bhaskar R Sathe, Dattatray J Late, Pravin S Walke (2019) Superior humidity sensor and photodetector of at room temperature. Ibid 293: 83-92.

69. Subha PP, Jayaraj MK (2019) Enhanced room temperature gas sensing properties of low temperature solution processed $\mathrm{ZnO} / \mathrm{CuO}$ heterojunction. BMC Chemistry 13(4).

70. Patil LA (2011) Room Temperature Ammonia Gas Sensing Using $\mathrm{MnO}_{2}$ Modified ZnO Thick Film Resistors. J Modern Physics 2(10): 1215-1221.

71. Mani GK, J Bosco J, Rayappan B (2013) A highly selective room temperature ammonia sensor using spray deposited zinc oxide thin film. Sensors and Actuators 183: 459- 466

72. Kruefu V, Anurat Wisitsoraat, Adisorn Tuantranont, Sukon Phanichphant (2014) Sensing properties of conducting polymer Au loaded $\mathrm{ZnO}$ nanoparticle composite materials. Nanoscale Research Letters 9(467).

73. Duo VT, Dang Thi Thanh Le, Nguyen Duc Hoa , Nguyen Van Duy, Chu Manh Hung, et al. (2019) New Design of ZnO Nanorod- and NanowireBased $\mathrm{NO}_{2}$ Room-Temperature Sensors Prepared by Hydrothermal Method. J Nanomaterials 6821937: 9.

74. Wang Z, Andre Sackmann, Shang Gao, Udo Weimar, Geyu Lu, et al. (2019) Study on highly selective sensing behaviour of ppb-level oxidizing gas sensor based on $\mathrm{Zn}_{2} \mathrm{SnO}_{4}$ nanoparticles immobilized on reduced graphene oxide under humidity conditions. Sensors \& Actuators 285: 590-560. 
75. Korotcenkov G, Brinzari V, Cho BK (2016) $\mathrm{In}_{2} \mathrm{O}_{3}$ - and $\mathrm{SnO}_{2}$-based thin film ozone sensors: fundamentals. J Sensors 3816094: 31.

76. Banichevich A, Peyerimhoff SD, Grein F (1990) Ab initio potential surfaces for ozone dissociation in its ground and various electronically excited states. Chem Phys 173(1): 1-6.

77. Tsai YT, Chang SJ, Tang IT, Hsiao YJ, Ji LW (2018) High density novel porous $\mathrm{ZnO}$ nanosheets based on a microheater chip for ozone sensors. IEEE Sens J 18(13): 5559-5565.

78. Ziegler D, Marchisio A, Montanaro L, Palmero P, Tulliani JM (2018) Barium hexaferrite thick-films for ozone detection at low temperature. Solid State Ion 320: 24-32.

79. Catto AC, Fiorido T, Souza ELS, Andres J, Aguir K, et al. (2018) Improving the ozone gas-sensing properties of $\mathrm{CuWO}_{4}$ nanoparticles. J Alloys Compd 748: 411-417.

80. Wu J, Tao K, Guo Y, Li Z, Wang X, et al. (2017) A 3D chemically modified graphene hydrogel for fast, highly sensitive, and selective gas sensor. Adv Sci 4(3): 1600319.

81. Hu J, Zou C, Su Y, Li M, Hu N, et al. (2017) Enhanced $\mathrm{NO}_{2}$ sensing performance of reduced graphene oxide by in situ anchoring carbon dots. J Mater Chem C 5: 6862-6871.

82. Li L, He S, Liu M, Zhang C, Chen W (2015) Three-dimensional mesoporous graphene temperature. Anal Chem 87: 1638-1645.

83. Gu F, Nie R, Han D, Wang Z (2015) $\mathrm{In}_{2} \mathrm{O}_{3}$-graphene nanocomposite based gas sensor for selective detection of $\mathrm{NO}_{2}$ at room temperature. Sens Actuators 219: 94-99.

84. Chen N, Li X, Wang X, Yu J, Wang J, et al. (2013) Enhanced room temperature sensing of $\mathrm{Co}_{3} \mathrm{O}_{4}$-intercalated reduced graphene oxide based gas sensors. Sens Actuators 188: 902-908.

85. Xia Y,Wang J, Xu JL, Li X, Xie D, et al. (2016) Confined formation of ultrathin $\mathrm{ZnO}$ nanorods/reduced graphene oxide mesoporous nanocomposites for high-performance room-temperature $\mathrm{NO}_{2}$ sensors. ACS Appl Mater Interfaces 8(51): 35454-35463.

86. Zhang H, Feng J, Fei T, Liu S, Zhang T (2014) $\mathrm{SnO}_{2}$ nanoparticles-reduced graphene oxide nanocomposites for $\mathrm{NO}_{2}$ sensing at low operating temperature. Sens Actuators 190: 472-478.

87. Liu S, Yu B, Zhang H, Fei T, Zhang T (2014) Enhancing $\mathrm{NO}_{2}$ gas sensing performances at room temperature based on reduced graphene oxideZn0 nanoparticles hybrids. Ibid 202: 272-278.

88. Chu X, Hu R, Wang J, Dong Y, Zhang W, et al. (2017) Preparation and gas sensing properties of graphene- $\mathrm{Zn}_{2} \mathrm{SnO}_{4}$ composite materials. Ibid 251: 120-126.

89. Li Y, Luo N, Sun G, Zhang B, Lin L, et al. (2018) In situ decoration of $\mathrm{Zn}_{2} \mathrm{SnO}_{4}$ nanoparticles on reduced graphene oxide for high performance ethanol sensor. Ceram Int 44: 6836-6842.

90. Thanh HX, Trung DD, Trung KQ Dam KV, Duy NV, et al. (2017) On-chip growth of single phase $\mathrm{Zn}_{2} \mathrm{SnO}_{4}$ nanowires by thermal evaporation method for gas sensor application. J Alloys Compd 708: 470-475.

91. Park S, An S, Ko H, Jin C, Lee C (2013) Enhanced $\mathrm{NO}_{2}$ sensing properties of $\mathrm{Zn}_{2} \mathrm{SnO}_{4}$-core/ZnO-shell nanorod sensors. Ceram Int 39(4): 3539-3545.

92. Liang YC, Lo YJ (2017) High-temperature solid-state reaction induced structure modifications and associated photoactivity and gas-sensing performance of binary oxide one-dimensional composite system. RSC Adv 7: 29428-29439.

93. Liu J, Li S, Zhang B, Xiao Y, Gao Y, et al. (2017) Ultrasensitive and low detection limit of nitrogen dioxide gas sensor based on flower-like $\mathrm{ZnO}$ hierarchical nanostructure modified by reduced graphene oxide. Sens Actuators 249: 715-724.

94. Chen R, Jing Wang, Yi Xia, Lan Xiang (2018) Near infrared light enhanced room-temperature $\mathrm{NO}_{2}$ gas sensing by hierarchical $\mathrm{ZnO}$ nanorods functionalized with $\mathrm{PbS}$ quantum dots. Sensors and Actuators 255(3): $2538-2545$.
95. Baratto C, Sberveglieri G, Onischuk, A, Caruso B, Di Stasio S (2004) Low temperature selective $\mathrm{NO}_{2}$ sensors by nanostructured fibres of $\mathrm{ZnO}$. Ibid 100(1-2): 261-265.

96. Zhu L, Zeng W (2017) Room-temperature gas sensing of ZnO-based gas sensor: A review. Ibid 267(1): 242-261.

97. Carotta MC, A Cervi, A Fioravanti, S Gherardi, A Giberti, et al. (2011) A novel ozone detection at room temperature through UV-LED-assisted ZnO thick film sensors. Thin Solid Film 520: 939-946.

98. Park S, An S, Mun Y, Lee C (2013) UV-enhanced $\mathrm{NO}_{2}$ gas sensing properties of $\mathrm{SnO}_{2}$-core/ZnO-shell nanowires at room temperature. ACS Appl Mater Interfaces 5(10): 4285-4292.

99. Zhang C, Xin Geng, Jiawei Li, Yifan Luo, Pengfei Lu (2017) Role of oxygen vacancy in tuning of optical, electrical and $\mathrm{NO}_{2}$ sensing properties of Zn01-x coatings at room temperature. Sens Actuators 248: 886-893.

100. Hsu CL, Chang LF, Hsueh TJ (2017) Light-activated humidity and gas sensing by $\mathrm{ZnO}$ nanowires grown on LED at room temperature. Ibid 249: $265-277$.

101. Espid E, Taghipour F (2018) Facile Synthesis and UV-Activated Gas Sensing Performance of Ag: ZnO Nano-Ellipsoids. ECS J Solid State Sci Technol 7(7): Q3089-Q3093.

102. Markiewicz N, Olga Casals, Cristian Fabrega, Isabel Gràcia, Carles Cané, et al. (2019) Micro light plates for low-power photoactivated (gas) sensors. Appl Phys Lett 114: 53508.

103. Casals 0, Nicolai Markiewicz, Cristian Fabrega, Isabel Gràcia, Carles Cané, et al. (2019) A parts per billion (ppb) sensor for $\mathrm{NO}_{2}$ with microwatt power requirements based on micro light plates. ACS Sens 4(4): 822-826.

104. Wagner R, Schönauer Kamin D, Moos R (2019) Novel Operation Strategy to Obtain a Fast Gas Sensor for Continuous ppb-Level NO2 Detection at Room Temperature Using ZnO-A Concept Study with Experimental Proof Sensors 19: 4104

105. Jacobs CB, Artem B Maksov, Eric S Muckley, Liam Collins, Masoud Mahjouri Samani, et al. (2017) UV-activated ZnO films on a flexible substrate for room temperature $\mathrm{O}_{2}$ and $\mathrm{H}_{2} \mathrm{O}$ sensing. Sci Reports 7: 6053.

106. Cui J, Linqi Shi, Tengfeng Xie, Dejun Wang, Yanhong Lina (2016) UVlight illumination room temperature $\mathrm{HCHO}$ gas-sensing mechanism of $\mathrm{ZnO}$ with different nanostructures. Sensors and Actuators 227: 220226.

107. Aleksanyan MS (2020) Study of the hydrogen peroxide vapors sensor under the influence of UV radiation. J Cont Phys Arm Acad Sci 55: 205212.

108. Zakaryan H, Aroutiounian V (2017) Investigation of cobalt doped tin dioxide structure and defects: Density functional theory and empirical force fields. Ibid: 227- 232.

109. Hunanyan AA, Aghamalyan MA, Aroutiounian VM, Zakaryan HA (2019) Formation Energy of Intrinsic and Impurity Defects in Tin Dioxide. Ibid 54: 282-286.

110. Aghamalyan MA, Tricoli Antonio, Santarossa Gianluca, Vargas Angelo, Baiker Alfons (2020) First-principles the interaction of $\mathrm{H}_{2} \mathrm{O}_{2}$ with the $\mathrm{SnO}_{2}$ (110) surface Ibid 55: 235-242.

111. Ghosh SK, M Berkowitz, RG Parr (1984) Transcription of groundstate density-functional theory into alocal thermodynamics (local temperature /entropy / electronic structure). Proc Natl Acad Sci 81(24): 8028-8031.

112. Giannozzi P, Andreussi O, Brummeet T, O Bunau, M Buongiorno Nardelli, et al. (2017) Advanced capabilities for materials modelling with Quantum ESPRESSO. J Phys Condens Matter 29(46): 465901.

113. Perdew JP, Burke K, Ernzerhof M (1996) Why semilocal functionals work: Accuracy of the on-top pair density and importance of system averaging. Phys Rev Lett 77: 3865-3872. 
114. Bader RFW (1990) Atoms in Molecules: A Quantum Theory. Oxford University Press.

115. Schierbaum KD, Kirner UK, Geiger JF, Göpel W (1991) ZnO thin film as methane sensor Different type of mechanisms of gas sensing. Sensors Actuators 4: 87-94.

\section{ISSN: 2574-1241}

DOI: $10.26717 /$ BJSTR.2020.30.004919

VM Aroutiounian. Biomed J Sci \& Tech Res

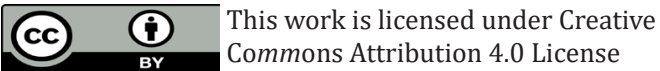

Submission Link: https://biomedres.us/submit-manuscript.php
116. Schierbaum KD, Wei Xing X, Göpel W (1993) An Experimental and Theoretical Investigation on the Solubility of Carbon Dioxide in Aqueous Solutions of Strong Electrolytes. Berichte der Bunsengesell schaft für Phys Chemie 97(1): 363-368.

117. (2020) Core/Shell Quantum Dots Synthesis, Properties and Devices (Eds. X. Tong и Z. M. Wang) Springer PH 2020.

\begin{tabular}{lll}
\hline BIOMEDICAL & Assets of Publishing with us \\
\hline RESEARCHES & Global archiving of articles \\
& - Immediate, unrestricted online access \\
\hline
\end{tabular}

